\title{
Performance-based assessment of cultural heritage assets: outcomes of the European FP7 PERPETUATE project
}

\author{
Dina D’Ayala · Sergio Lagomarsino
}

Received: 24 November 2014 / Accepted: 25 November 2014 / Published online: 11 December 2014

(C) The Author(s) 2014. This article is published with open access at Springerlink.com

The damage assessment to cultural heritage assets after recent earthquakes, in particular in Italy (Umbria and Marche, 1997; L'Aquila, 2009; Emilia, 2012), showed the high vulnerability of some types of historical structures (palaces, churches, towers etc.). Earthquakes also proved that strengthening interventions adopted in the last decades are often invasive, ineffective and might also increase the vulnerability. Thus, there is an urgent need for developing reliable assessment procedures and promoting effective strategies for the seismic risk mitigation of cultural heritage .

The preservation of cultural heritage assets must guarantee their capacity to last over time against decay, natural hazards and extreme events, without losing their authenticity and use.

A strong engineering contribution on assessment and strengthening methods for historic and heritage buildings was developed in the latter part of the twentieth century in Europe and the Mediterranean Region. In particular, ICOMOS and ICCROM have promoted an important campaign to raise awareness on structural conservation through the writings of Sir Bernard Feilden (1987) and the constitution of an ICOMOS International Scientific Committee for the Analysis and Restoration of Structures of Architectural Heritage (ISCARSAH) in 1996, which led to the adoption of the ISCARSAH Principles in 2003.

The growing attention to this topic is demonstrated by the European Commission's funding of two large consortia that had submitted a research proposal under the call FP7-ENV-2009-1, on the effect of natural hazards on the cultural heritage, specifically earthquake.

The PERPETUATE project (Performance Based Approach to Earthquake protection of Cultural Heritage in European and Mediterranean Countries) had as main objective to produce European Guidelines for the evaluation and mitigation of seismic risk to cultural heritage assets, useful to support the design of strengthening interventions for the preservation of the architectural building and the contained unmovable artworks. The ambition was to develop

D. D'Ayala (西)

University College of London, London, UK

e-mail: d.dayala@ucl.ac.uk

S. Lagomarsino

University of Genoa, Genoa, Italy 
a procedure that could be conceptually included in the same framework of those proposed worldwide for the seismic performance-based assessment (PBA) of ordinary existing buildings.

In the PERPETUATE project the displacement-based approach is adopted as standard method of analysis, which require the assessment to be performed using non linear analytical methods. Nonlinear static (pushover) analyses are recommended as the most effective approach while non linear dynamic analyses are suggested as an alternative to study some specific type of assets.

A full methodological path for the assessment of cultural heritage assets is proposed, including: (1) definition of performance limit states (specific for architectural and artistic assets); (2) evaluation of seismic hazard and soil-foundation interaction; (3) construction knowledge (non-destructive testing, material parameters, structural identification); (4) structural modelling and seismic analysis of masonry structures and unmovable artistic assets; (5) verification procedures; (6) rehabilitation decisions and design of strengthening.

One other important evidence, emerging from the destruction caused by the earthquake in L'Aquila and in the neighbouring villages, was that every single historic building had been affected, from the humblest of dwelling to the city's Cathedral. This pointed out the necessity to deal with the problem at two different scales: that of the single monumental asset and that of the city and the surrounding territory, involving many similar buildings and their interaction. Assessment of vulnerability and risk of many buildings cannot be dealt using the same tools as the ones developed for analysis of single assets, none the less the outputs obtained at the two scales need to be commensurable and comparable, so that decision taken at district level can be implemented and refined at the level of the single building. To ensure this a similar methodological path for the district as the one for the single asset was developed within the PERPETUATE project, identifying the tools most suitable at territorial scale, while ensuring the adoption of the displacement-based approach.

This special issue, entitled "Performance-Based Assessment of Cultural Heritage Assets: Outcome of The European Project PERPETUATE" presents the framework developed within the project and its application to a number of case studies. It focuses mainly on assessment procedures; it is in this respect that novel results have been reached, both conceptually and from an operational point of view.

The issue contains 19 papers. The first one, by Lagomarsino and Cattari (2014), "PERPETUATE guidelines for seismic performance-based assessment of cultural heritage masonry structures", illustrates the general framework of the Guidelines. The wide variety of architectural assets is classified and the related modeling strategies are identified; moreover, immovable artistic assets are considered in the assessment. A displacement-based approach is adopted, as these structures rely on displacement capacity to survive earthquakes. Safety and conservation requirements are proposed by considering distinct sets of performance levels, related to use and safety of people, conservation of the building and of the artistic assets that might be present.

The following six papers investigate separately the components of the assessment approach.

The paper by Douglas et al. (2014) entitled "Evaluation of seismic hazard for the assessment of historical elements at risk: description of input and selection of intensity measures", deals with the distinctive features of the seismic hazard assessment within the framework of historical assets, including a consideration of the appropriate return period to be used for such elements at risk. The intensity measures that could be used to describe earthquake shaking for the analysis of different classes of historical assets are discussed, as well as available 
approaches for their assessment. Site effects due to steep topography, basin effect and the possibility of large lenses of detritus underneath the foundations are discussed.

The specific effects of fault rupture and of large ground displacement are investigated in detail in the contribution by Loli et al. (2014) "Nonlinear analysis of earthquake fault rupture interaction with historic masonry buildings". The authors set out a nonlinear 3D finite element model to reproduce the response of the rupturing soil, as well as the masonry structure. Several characteristic mechanisms of soil-structure interaction are considered. The observed failure pattern and the structural damage are shown to depend strongly on the exact position of the structure relative to the fault. Alleviation of tectonic risk through foundation enhancement/improvement is investigated by considering alternative foundation systems. Results highlight the advantageous performance of rigid embedded and continuous foundations as opposed to more flexible and isolated supports, indicating that foundation strengthening may provide important shielding against settlement and structural drift.

Determining realistic values of dynamic stiffness of historic building foundation is hence fundamental to an appropriate assessment of their response. This issue is treated in the paper by Pitilakis and Karatzetzou (2014), "Dynamic stiffness of monumental flexible masonry foundations", which proposes reduction factors to account for the decrease of stiffness of monumental masonry foundations due to aging, weathering or other deteriorating effects. The proposed reduced stiffness values can be readily used in finite element structural analysis software in the framework of PBA. Taking into account realistic foundation-soil system flexibility and soil-foundation interaction at low-frequency, the procedure allows to reduce monumental masonry foundation-wall stiffness from the rigid-footing assumption, to the relative stiffness between the foundation and the soil. Application to a real case shows natural period elongation and ductility increase.

In developing robust numerical approaches to the assessment of the seismic vulnerability of either single assets or large number of historic buildings, it is essential that the models are able to capture all possible modes of failure. In masonry buildings, with modest tensile strength, such failure modes are highly affected by pre-existing crack patterns, due to previous earthquakes or other causes. The paper by Novelli and D' Ayala (2014) "LOG-IDEAH: LOGic trees for identification of damage due to earthquakes for architectural heritage", presents a post-earthquake assessment tool for the evaluation of the global seismic performance of architectural assets, developed in the framework of PERPETUATE. LOG-IDEAH is a webbased interactive tool which interprets the seismic damage collected on site by relying on vulnerability assessment expert knowledge. It is encoded in answer set programming to replicate the logic/intuitive process surveyors use to investigate the causes of damage and to correlate crack patterns with failure modes. LOG-IDEAH (available at http://perpetuate.cs. bath.ac.uk/) allows with simple tools to sketch both the geometry of the construction and the distribution of observed cracks at the level of structural elements and macroelements. It then uses this information, interpreted at the global level, to provide all possible failure modes and related possibilities of occurrence by taking into consideration the reliability level of the collected data. The procedure is validated by application to damaged buildings in L'Aquila.

In Novelli et al. (2014) "A procedure for the identification of the seismic vulnerability at territorial scale. Application to the Casbah of Algiers", an analytical approach is proposed to determine the seismic vulnerability of large historic urban districts, where interaction among single units is critical to their seismic response. Such approach consists of ten steps, providing advice on how to select building samples in the area of study, how to compute the seismic performance of buildings and, finally, how to evaluate rehabilitation decisions to reduce the seismic fragility of the studied typologies over an entire district or city. The procedure is illustrated by way of application to the Casbah of Algiers. Pre-existing seismic damage, decay 
and the complexity of the urban lay-out make this application particularly challenging. The seismic vulnerability assessment method underpinning the 10-step procedure is FaMIVE (Failure Mechanism Identification and Vulnerability Evaluation), a mechanical approach based on limit state analysis and kinematics, which allows computing collapse load factors and mechanisms, deriving capacity curves and determining fragility functions; moreover, it provides a base for evaluating the effects of strengthening interventions at territorial level. One of the outcomes of the damage assessment, in both L'Aquila and Algiers, is the high proportion of buildings failing by out-of-plane mechanisms.

Few numerical tools exist to accurately simulate such failure modes. A comparison of such methods is offered in Lagomarsino (2014) "Seismic assessment of rocking masonry structures". Incremental Dynamic Analyses have been performed by adopting different nonlinear models (Housner rigid block model, bi-linear elastic model with equivalent viscous damping), in order to single out the thresholds associated to the attainment of different limit states. A displacement approach based on an incremental limit analysis of rigid blocks is proposed for the PBA of rocking masonry structures, such as: rocky structures (archaeological remains, obelisks, columns, trilithons), arch-piers systems (e.g. triumphal arches, belfries), out-of-plane mechanisms of walls (standing out walls, façades in buildings or churches etc.) or artistic assets prone to overturn (pinnacles, statues etc.). The method is compatible with the format of the PERPETUATE performance-based assessment method for cultural heritage assets.

The uncertainty associated with the use of different simplified numerical models choices and knowledge of specific structural configurations on the assessment of the vulnerability of historic masonry buildings is illustrated in the paper by Bosjlikov et al. (2014) "Evaluation of uncertainties in determining the seismic vulnerability of historic masonry buildings in Slovenia: use of macro-element and structural element modelling". Two case studies were used to compare different methods. In the rural area, the accuracy in predicting failure modes ranged between 50 and $80 \%$ of the stock of building; the most critical failure mechanisms were due to out-of-plane loading. Given the uncertainties associated with the data relative to the urban architecture stock, the analysis was carried out considering different hypotheses, leading to a range of 30-70\% damaged buildings, for 475 years return period, with diverse failure mechanisms and ultimate capacity depending on specific structural assumptions. For one building of rural architecture already damaged during previous earthquake in 2004, where due to the extensive in-situ campaign the influence of uncertainties were minimised, direct comparison of the effectiveness of both methods were investigated.

A common feature of all the previous articles is the need to determine the robustness of the modelling choices pursued, the reliability of their results and their applicability to a wide range of problems so as to be worth of being included in guidelines. The following two papers provide the conceptual harmonization and the tools needed to measure such reliability for the whole PERPETUATE framework.

Stemming from the paradigm that relates the concept of safety to the level of knowledge acquired and the tools used for the assessment, the paper by Cattari et al. (2014a), "Sensitivity analysis for setting up the investigation protocol and defining proper confidence factors for masonry buildings", sets out to use systematic sensitivity analysis, to identify in a more robust manner the parameters that affect the response and for which confidence factor should be coherently determined. This allows to establish a strict correlation between investigations and the assessment procedure. Main attention is given to the application of the procedure to buildings with a significant cultural value, where the minimization of invasiveness of investigations and balance of costs play a crucial role for successful conservation. 
Complementary to this paper is the one by Kržan et al. (2014a) "Acquiring reference parameters of masonry for the structural performance analysis of historical buildings", which investigates the minimum requirements for laboratory and in-situ testing for cultural heritage assets. This state-of-the-art paper is organized with integrated outcomes from the test campaigns carried out during the PERPETUATE project. Reference material parameters are provided both for brick and stone masonry, together with their upper and lower bound values for both mechanical properties and damage limits, to which performance limit states may be associated. Besides the limit states for structural elements, the relevant ones for artistic assets connected to structural elements are also presented.

The large experimental campaign developed during the PERPETUATE project is illustrated in five papers that investigate specific issues of seismic behaviour of heritage assets for which a dearth of data exist in literature. The first one is on the use of ambient vibrations to determine the characteristics of both the monumental building and its foundation. Karatzezou et al. (2014a), "Ambient vibration measurements on monuments in the Medieval City of Rhodes, Greece", performed a number of ambient vibrations measurements on three selected monuments in the Medieval City of Rhodes (Greece) and the surrounding soil site. The Frequency Domain Decomposition technique is adopted for ambient modal identification using ARTeMIS software and the continuous wavelet transformation for calculating the wavelet energy to compare it with the pathology pattern of a typical masonry wall. The dynamic properties of the foundation soil, in terms of shear-wave velocity, were also explored using the Spatial Autocorrelation Coefficient method. The updating of the initial numerical model using the results of the ambient vibrations measurements shows the usefulness of the approach and provides some helpful practical guidelines.

In the second one, by Calderini et al. (2014a), "In-plane shear tests on masonry panels with plaster: correlation of structural damage and damage on artistic assets", a combination of destructive and non-destructive tests were conducted to establish correlation between damage levels in the structural elements and damage levels in the plaster, on brickwork and stonemasonry fabric. The results are influenced by the masonry type and needs to be properly interpreted depending on the type of test adopted.

Simonič et al. (2014) "In-situ and laboratory tests of old brick masonry strengthened with FRP in innovative configurations and design considerations", investigate the relationship between in-situ and laboratory testing and the effectiveness of strengthening masonry panels by FRP strips. Two sets of in-situ experiments were performed on 12 old walls, belonging to two buildings made of solid bricks in low strength mortar. A third set of tests was performed in the laboratory on 16 specimens made of contemporary solid bricks in good lime-cement mortar. Tests were performed with different reinforcement configurations. Carbon FRP strips were epoxy-bonded horizontally, diagonally or combined (horizontally and vertically). Glass FRP grids were placed in the modified cement mortar over the entire surface of the wall. Specimens were tested under constant vertical load and by displacement controlled horizontal cyclic loading. The carbon fibre reinforced polymer strengthening significantly increased the ultimate displacement capacity in case of the horizontal and combined strengthening. The diagonal strengthening was not so effective because the failure was governed by the peeling of strips from the masonry. The GFRP grid configuration greatly increased the load bearing capacity but not the ultimate displacement. The shear strength of the strengthened and unstrengthened specimens is compared to the calculated values of the seismic shear load bearing capacity proposed in the design guides ACI 440.7R-10 (2010) and CNR-DT 200/2004.

The use of shaking table test is reported in the last two papers on experimental techniques. The one by Drosos and Anastasopoulos (2014), "Experimental investigation of the seismic response of classical temple columns", investigates the response of classical columns made 
of drums, by constructing physical models of such multi-drum columns at reduced scale and testing them at the shaking table of the NTUA Laboratory of Soil Mechanics. The marble specimens were excited by idealized Ricker wavelets and real seismic records. The tested multi-drum columns were proven to be very earthquake-resistant. Even when subjected to the strongest motions ever recorded in Greece, their permanent deformation was minimal. The second paper by Calderini et al. (2014b) "Shaking table tests of an arch-pillars system and design of strengthening by the use of tie-rods", investigated the effectiveness of flexible tie-rods to improve the seismic response of the arch-pillars system by means of shaking table tests and simple analytical models, developed in the framework of displacement-based design. The reduced scale model, made of rigid blocks with dry joints, has been tested without tie-rod and considering different configurations of strengthening. Both experimental and theoretical results have proved the importance, in particular for this kind of masonry structure, of improving displacement capacity rather than strength, because in this latter case other brittle mechanisms could be activated. The paper also shows the possibility of describing the seismic response of rocking masonry structures, characterized by complex mechanisms made of many blocks and hinges, by an equivalent nonlinear SDOF system.

The last four papers illustrate the application to some specific monumental buildings of the comprehensive framework developed in the PERPETUATE project for the PBA.

Cattari et al. (2014b) "Vulnerability assessment of Hassan Bey's Mansion in Rhodes", illustrates a comprehensive application of the PERPETUATE Guidelines to a typical masonry building. The paper is focused on the use of sensitivity analysis for the identification of the main parameters that affect the structural response of the building when performing non-linear static pushover analysis. Uncertainties considered in this application are both aleatory and epistemic. The epistemic uncertainties concern the effectiveness of the infilled openings: in fact, this feature strongly characterizes this building that has been subjected to many transformations along its life. Moreover, seven random variables have been considered to account for the aleatory uncertainties: they involve the material properties, the material constitutive law as well as the horizontal diaphragms stiffness. The results are expressed in terms of safety factor for different performance requirements and return periods.

The paper by Rossi et al. (2014) "Application of different models for the seismic assessment of the Great Mosque of Algiers", deals with another type of monumental buildings, those characterized by a wide open space and the need to consider different independent macroelements. The effect of the choice of modelling strategy, corresponding to the assumption of different possible seismic behaviours is investigated. In the case of the Great Mosque both the current state of the building and a virtual strengthened condition are analysed. It is worth noting that, while in the current state the seismic behaviour of the asset is well described by a set of macroelements that may be analysed independently (through 2D models), in the second case the strengthening intervention leads to the adoption of a 3D global model Three different modelling strategies of different complexity are discussed: the finite element model, the macro-block model and the equivalent frame approach. The results of nonlinear analyses performed (static and kinematic) constitute the main tool to interpret the seismic response of the asset, perform the PBA and address the choice on the rehabilitation decisions.

Kržan et al. (2014b) "Application of different in-situ testing techniques and vulnerability assessment of Kolizej palace in Ljubljana", investigated the effect of deterioration on a monumental building that was abandoned for a long period. Prior to its demolition in 2011 extensive on-site investigation was carried out, providing valuable data regarding the influence of the deteriorated masonry on the seismic response of the building. Experimental tests proved almost completely saturated moisture conditions in the ground level of the building, while all the stories above were in almost dry condition. The deterioration and the satura- 
tion affected both strength and stiffness properties of the in-situ masonry to a large extent. Regardless of the adopted modelling strategies, the vulnerability assessment of the Kolizej Palace has proved that the building in its latest condition was far behind the current code requirements in respect to both static and seismic demand.

Finally Karatzezou et al. (2014b), "Soil-foundation-structure interaction and vulnerability assessment of the Neoclassical School in Rhodes, Greece", have focused on the application of the PERPETUATE methodology considering the effects of both soil-foundation-structure interaction (SFSI) and masonry foundation flexibility on the building response, before and after rehabilitation design measures. It is found that SFSI and foundation flexibility produce larger displacements and reduce the maximum ground acceleration that the building can sustain by over $50 \%$. However, despite the detrimental effects of SFSI on the acceleration capacity, SFSI and foundation flexibility may have a favourable effect on the structural safety, as they modify the collapse mechanism. The results of seismic analyses showed the building, in its current state, does not sustain the demands for the Life Safety and Collapse Prevention performance levels. Stiffening the roof of the structure and providing sufficient connections to the structure, along with systematic grouting of the masonry walls, are the principal rehabilitation decisions considered herein. Mitigation measures were evaluated, considering SFSI and the analyses revealed the adequacy of the proposed retrofitting measure.

We believe these 19 papers well represent the efforts and achievements of the consortium in delivering the project. Some very important results were achieved and new tools have been produced that can be of generic use in performing the vulnerability assessment of single and samples of existing buildings using the performance-based approach. Such tools can provide robust methods for determining the most appropriate adaptation and mitigation strategy, by meeting both safety and conservation requirements.

As Guest Editors of this issue of the Bulletin, we would like to extend a sincere thanks to the authors, for the interesting and original contributions, and to the international panel of reviewers, for their insight and advice in the process of improving the original submissions. Most importantly, we would like to express special thanks to the Editor of the Bulletin of Earthquake Engineering, Prof. Attila Ansal, for its essential guidance in producing this issue, and to the technical staff of Springer, for the continuous technical assistance provided throughout the publishing process. Final thanks go to the interested readers' community.

Open Access This article is distributed under the terms of the Creative Commons Attribution License which permits any use, distribution, and reproduction in any medium, provided the original author(s) and the source are credited.

\section{References}

Bosjlikov V, D’Ayala D, Novelli V (2014) Evaluation of uncertainties in determining the seismic vulnerability of historic masonry buildings in Slovenia: use of macro-element and structural element modelling. doi:10. 1007/s10518-014-9652-7

Calderini C, Degli Abbati S, Cotič P, Kržan M, Bosiljkov V (2014a) In-plane shear tests on masonry panels with plaster: correlation of structural damage and damage on artistic assets. doi:10.1007/s10518-014-9632-y

Calderini C, Lagomarsino S, Rossi M, De Canio G, Mongelli ML, Roselli I (2014b) Shaking table tests of an arch-pillars system and design of strengthening by the use of tie-rods. doi:10.1007/s10518-014-9678-X

Cattari S, Lagomarsino S, Bosiljkov V, D'Ayala D (2014a) Sensitivity analysis for setting up the investigation protocol and defining proper confidence factors for masonry buildings. doi:10.1007/s10518-014-9648-3

Cattari S, Lagomarsino S, Karatzezou A, Pitilakis D (2014b) Vulnerability assessment of Hassan Bey's Mansion in Rhodes. doi:10.1007/s10518-014-9613-1 
Douglas J, Seyedi DM, Ulrich T, Modaressi H, Foerster E, Pitilakis K, Pitilakis D, Karatzetzou A, Gazetas G, Garini E, Loli M (2014) Evaluation of seismic hazard for the assessment of historical elements at risk: description of input and selection of intensity measures. doi:10.1007/s10518-014-9606-0

Drosos VA, Anastasopoulos I (2014) Experimental investigation of the seismic response of classical temple columns. doi:10.1007/s10518-014-9608-y

Feilden BM (1987) Between two earthquakes: cultural property in seismic zones. ICCROM, Rome

Karatzezou A, Negulescu C, Manakou M, Benjamin F, Seyedi DM, Pitilakis D, Pitilakis K (2014a) Ambient vibration measurements on monuments in the Medieval City of Rhodes, Greece. doi:10.1007/ s10518-014-9649-2(15)

Karatzezou A, Pitilakis D, Kržan M, Bosiljkov V (2014b) Soil-foundation-structure interaction and vulnerability assessment of the neoclassical School in Rhodes, Greece. doi:10.1007/s10518-014-9637-6

Kržan M, Gostič S, Bosiljkov V (2014a) Application of different in-situ testing techniques and vulnerability assessment of Kolizej palace in Ljubljana. doi:10.1007/s10518-014-9639-4

Kržan M, Gostič S, Cattari S, Bosiljkov V (2014b) Acquiring reference parameters of masonry for the structural performance analysis of historical buildings. doi:10.1007/s10518-014-9686-x

Lagomarsino S (2014) Seismic assessment of rocking masonry structures. doi:10.1007/s10518-014-9609-X

Lagomarsino S, Cattari S (2014) PERPETUATE guidelines for seismic performance-based assessment of cultural heritage masonry structures. doi:10.1007/s10518-014-9674-1

Loli M, Anastasopoulos I, Gazetas G (2014) Nonlinear analysis of earthquake fault rupture interaction with historic masonry buildings. doi:10.1007/s10518-014-9607-z

Novelli VI, D'Ayala D (2014) LOG-IDEAH: LOGic trees for identification of damage due to earthquakes for architectural heritage. doi:10.1007/s10518-014-9622-0

Novelli VI, D’Ayala D, Makhloufi N, Benouar D, Zekagh A (2014) A procedure for the identification of the seismic vulnerability at territorial scale. Application to the Casbah of Algiers. doi:10.1007/ s10518-014-9666-1

Pitilakis D, Karatzetzou A (2014) Dynamic stiffness of monumental flexible masonry foundations. doi:10. 1007/s10518-014-9611-3

Rossi M, Cattari S, Lagomarsino S (2014) Application of different models for the seismic assessment of the Great Mosque of Algiers. doi:10.1007/s10518-014-9682-1

Simonič MJ, Gostič S, Bosiljkov V, Žarnić R (2014) In-situ and laboratory tests of old brick masonry strengthened with FRP in innovative configurations and design considerations. doi:10.1007/s10518-014-9644-7 